\title{
Impact of incarceration in Nazi concentration camps on multimorbidity of former prisoners
}

\author{
This article was published in the following Dove Press journal: \\ Neuropsychiatric Disease and Treatment \\ II March 2015 \\ Number of times this article has been viewed
}

\author{
Robert K Jablonski' \\ Jerzy Leszek ${ }^{2}$ \\ Joanna Rosińczuk ${ }^{3}$ \\ Izabella Uchmanowicz ${ }^{4}$ \\ Bernard Panaszek' \\ 'Department and Clinic of Internal \\ Diseases, Geriatry and Allergology, \\ ${ }^{2}$ Department of Psychiatry, \\ ${ }^{3}$ Department of Nervous System \\ Diseases, Department of Clinical \\ Nursing, ${ }^{4}$ Division of Nursing \\ in Internal Medicine Procedures, \\ Department of Clinical Nursing, \\ Wroclaw Medical University, \\ Wroclaw, Poland
}

Objective: To show the extent to which the health of former prisoners was affected by incarceration in extermination camps after 5 and 30 years of leaving the camp, and to determine the etiological factors underlying particular dysfunctions.

Methods: Medical records of former prisoners developed in $1950(n=250)$ and $1975(n=120)$ were then, after several decades, retrospectively analyzed and compared with the control group, randomized and matched according to age, sex, occupation, and environment. None of the subjects in the control group was a prisoner either at a concentration camp or at any other prison or detention facility.

Results: Multimorbidity affected mainly the central nervous system (CNS). Five years after leaving a camp, CNS dysfunctions were observed in $66 \%$ of former prisoners. Skeletal $(42.4 \%)$ and cardiovascular system (34.4\%) dysfunctions were the second and third most frequent dysfunctions. Thirty years after leaving a camp, the most prevalent coexisting conditions were also found within the CNS (80\%), cardiovascular system (58.33\%), and skeletal system (55\%). Five and 30 years after leaving a camp, multiorgan lesions were found in $21.6 \%$ and $60 \%$ of survivors, respectively. Multimorbidity was more frequent in a group of prisoners who underwent the state of apathy and depression or who had been incarcerated longer than 24 months. The rate of CNS diseases was four times higher, and the rate of cardiovascular diseases or skeletal system dysfunctions was two times higher, in the study group after 30 years of leaving a camp compared with the control group.

Conclusion: The consequences of incarceration in concentration camps manifesting as multimorbidity, premature aging, and dramatic increase in mortality rate are observed in the majority of former prisoners. The multimorbidity mostly affected older prisoners who stayed at a camp for a longer time period.

Keywords: concentration camp syndrome, cachexia, low-grade systemic inflammation

\section{Introduction}

Multimorbidity is the co-occurrence of multiple chronic medical conditions in one person, and is a major issue in modern medicine. It correlates with age, and, according to one interesting hypothesis, there is probably a common pathomechanism responsible for multimorbidity, namely low-grade systemic inflammation. Cellular and cytokine mechanisms triggered by this inflammatory pattern seem to resemble the mechanisms that lead to wasting diseases. ${ }^{1}$ Cachexia, expressed as body weight loss, apathy, and depression among prisoners, could be a significant mechanism of multimorbidity in camps where different life-threatening conditions were very common.

The history of concentration camps dates back to 1900 . The British set up concentration camps in modern-day South Africa during the Boer Wars, after they defeated the African troops and had taken most of the territory of the Transvaal Republic and Orange Free State. The British Empire decided to exterminate the Boer people and started
Correspondence: Joanna Rosińczuk

Department of Nervous System

Diseases, Department of Clinical Nursing,

Wroclaw Medical University, K Bartla 5,

5I-618 Wroclaw, Poland

Email joanna.rosinczuk@umed.wroc.pl
Neuropsychiatric Disease and Treatment 2015:II 669-674 
setting up concentration camps which lead to 27,927 Boers being killed. ${ }^{2}$ The Germans used a similar policy against the people who lived in their colonies and set up concentration camps in the German East Africa (Tanganyika) and SouthWest Africa (today the Republic of Namibia)., ${ }^{3,4}$ Poor conditions caused permanent health deterioration, and extreme physical effort and starvation led to weight loss, cachexia, apathy, and depression. Multiple negative factors underlying various dysfunctions plus malnutrition could cause one prisoner to suffer from multiple diseases at a time.

The aim of this study was to show the extent to which the health of former prisoners was affected by incarceration in extermination camps after 5 and 30 years of leaving a camp compared with a population who had never been incarcerated, and to determine the etiological factors underlying particular dysfunctions.

\section{Materials and methods}

The study group was evaluated on the basis of questionnaires administered to 250 former prisoners, including 200 men and 50 women who were medically examined in 1950, ie, 5 years after leaving a concentration camp, and 120 of the same former prisoners, including 100 men and 20 women who were medically examined in 1975, ie, 30 years after leaving a concentration camp. The group of 250 survivors included 155 professionals and 95 manual workers, who were aged 19 to 60 years. The group of 120 survivors interviewed in 1975 included 50 professionals and 70 manual workers, aged 39 to 85 years. The time of incarceration ranged from 6 months to 60 months. Each subject was interviewed and underwent a medical examination, and some additional tests were carried out: urinalysis, morphology, erythrocyte sedimentation rate, chest X-ray, and electrocardiography. Specialist tests were also conducted, if necessary, by ophthalmologists, otolaryngologists, psychiatrists, neurologists, urologists, and gynecologists. Out of 250 subjects examined in 1950, 120 lived to 1975 . They were interviewed, medically examined, and also subjected to laboratory tests. The control group in 1950 included 250 subjects, 200 men and 50 women, and in 1975 it included 120 subjects, 100 men and 20 women, who were randomized from the 1950 control group according to their age, sex, occupation, and environment to match the study group. None of the subjects in the control group had been a prisoner either at a concentration camp or any other prison or detention facility. The control group was also interviewed and medically examined.

This project was approved by the Ethics Committee of Wroclaw Medical University, Wroclaw, Poland (decision number KB-31/2011). The patients' consent was not obtained; because the researchers analyzed the medical records of patients several decades after they had been produced, physicians had taken care of those patients at that time (retrospective work). The researchers did not have the chance to meet these patients to ask for their permission, so patient records were anonymous and de-identified prior to analysis.

\section{Results}

The medical examination of 250 former prisoners of concentration camps 5 years after leaving the camp found the coexistence of multiple diseases, whereas no dysfunction was found in $74 \%$ of subjects in the control group, showing that the coexistence of multiple diseases (multimorbidity rate) in former prisoners immediately after leaving the camp was much higher than in subjects who had never been incarcerated, and affected almost all systems: the central nervous system (CNS) (66\% versus 6\% in the control group), the skeletal system (42.4\% versus $4.8 \%$ in the control group), cardiovascular system $(34.4 \%$ versus $10 \%$ in the control group), and alimentary system (26\% versus $3.2 \%$ in the control group). Figure 1 shows the exact percentage of lesions within particular systems in former prisoners of concentration camps compared with the control group.

On the basis of questionnaires and comparative analysis of the study group and control group, the condition of 120 former prisoners deteriorated substantially within 30 years after leaving the camp. This was due to the extreme conditions at the camps, famine, contagious diseases (mainly typhus and typhoid fever), injuries (mainly head injury), beating and torture, and pseudo-medical experiments, whose effects often became visible many years later. Lesions affected almost all systems. However, the most common were dysfunctions within the CNS, which manifested in $80 \%$ of survivors, including anxiety neurosis, depressive and vegetative neurosis, anxiety-depressive disorder, and depression. Furthermore, single cases of psychosis, posttraumatic epilepsy, Parkinson's disease, and dementia were reported. In the control group, only $24 \%$ of subjects manifested some lesions. Cardiovascular and skeletal system dysfunctions were the second and third most frequent dysfunctions manifested by former prisoners (respectively, $58.3 \%$ versus $35 \%$ in the control group, and $55 \%$ versus $26.6 \%$ in the control group). Less predominant than the three systems mentioned above were lesions of the respiratory system $(25 \%$ versus $15.8 \%$ in the control group), alimentary system (20\% versus $14.1 \%$ in the control group), urinary system $(13.3 \%$ versus $8.3 \%$ in the 


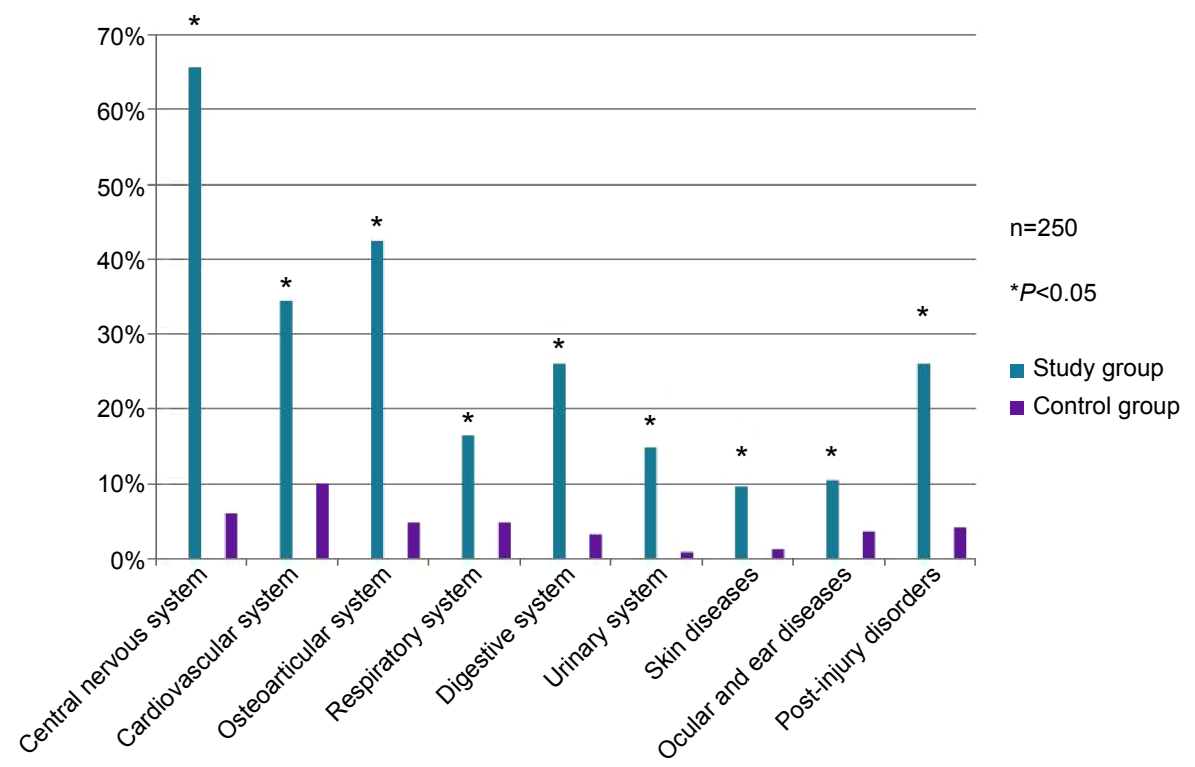

Figure I Morbidity in the group of prisoners evaluated in 1950.

control group), and vision and hearing (17.5\% versus $8.3 \%$ in the control group). Posttraumatic lesions were also very common and affected $48.4 \%$ of former prisoners but only $4.1 \%$ in the control group. More details about the percentage of lesions within the particular systems (multimorbidity) in former prisoners of concentration camps compared with the control group are shown in Figure 2.

Multimorbidity in former prisoners is characterized by the coexistence of multiple organ or system lesions. The examination in 1950 found lesions of two or more organs in $64.8 \%$ of former prisoners and only in $8 \%$ in the control group, where
$74 \%$ of subjects manifested no dysfunction. More details about the percentage of multimorbidity in the study group versus control group are shown in Figure 3. The examination in 1975 found that $89.17 \%$ of former prisoners were affected by multiple organ or system lesions and only $10.8 \%$ by a single organ lesion, as shown in Figure 4. In the control group, multiple lesions were noted in $44.16 \%$ of subjects, with a single organ lesion in 55.8\%, as shown in Figure 4.

The follow-up data from 1975 show that multimorbidity was predominant among subjects aged 61 to 70 years, ie, in 64 former prisoners (53.3\%), as shown in Figure 5.

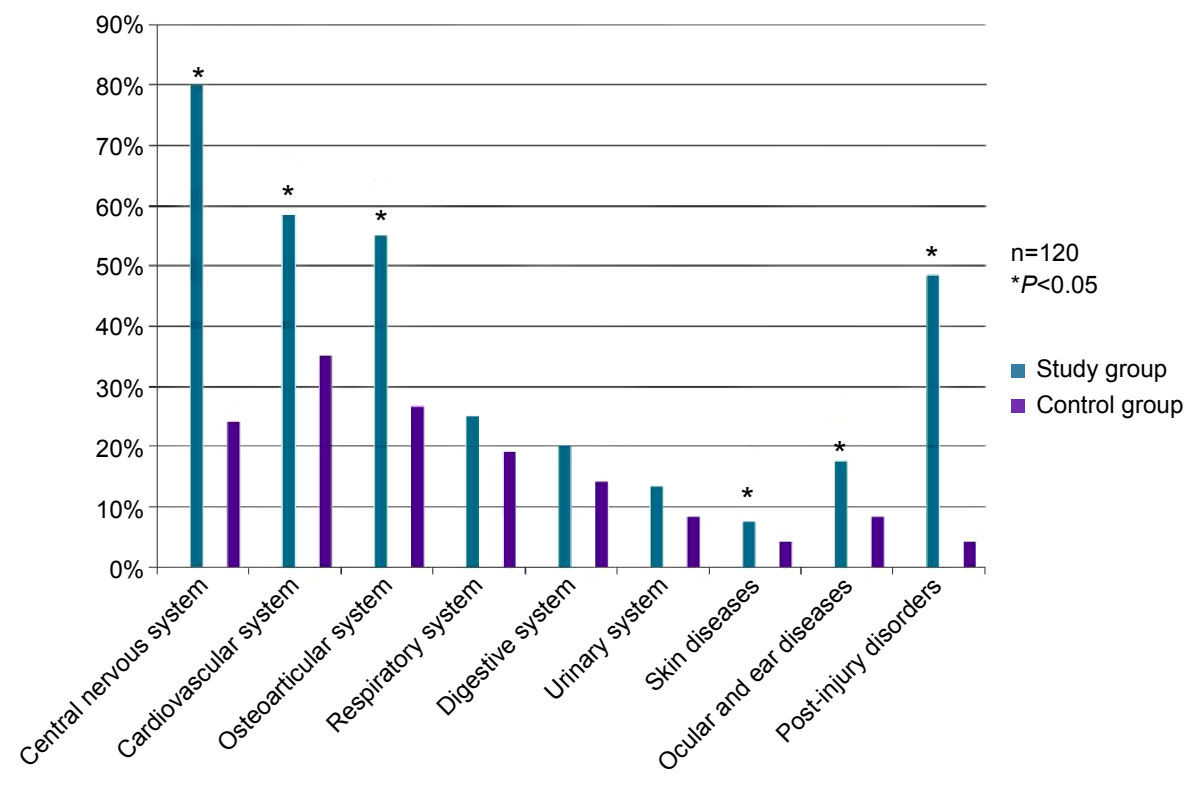

Figure 2 Morbidity in the group of prisoners evaluated in 1975. 


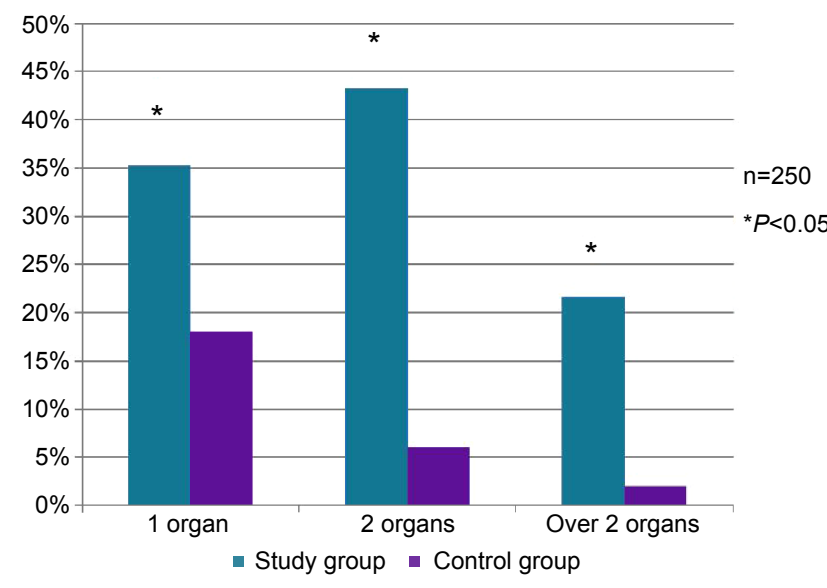

Figure 3 Multimorbidity in the group of prisoners evaluated in 1950.

In addition to this, $83 \%$ of former prisoners who had been incarcerated for a period of 25 months to 36 months had multisystemic lesions. Generally, prisoners who stayed at a camp longer than 24 months more frequently manifested multisystemic lesions compared with prisoners incarcerated for up to 24 months, as shown in Figure 6.

All of the former prisoners demonstrated psychiatric symptoms of KZ-syndrome/posttraumatic stress disorder, mainly depression, anxiety, sleep disorders, hyperactivity, emotional disturbances, and personality disorders, which were not observed in the control group.

\section{Discussion}

Our findings have clinical and ethical aspects, observed in the contemporary world in the regions of ethnic and religious conflicts. Clinically, results of these studies show that the organism exposed to extreme stimuli and threats is susceptible to the occurrence of many diseases, especially disorders of the CNS. Present times abound with such threats in the

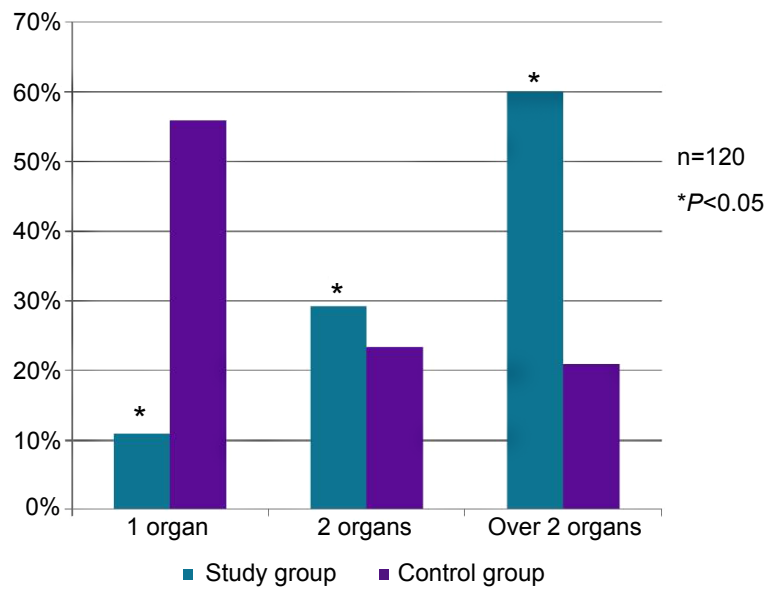

Figure 4 Multimorbidity in the group of prisoners evaluated in 1975.

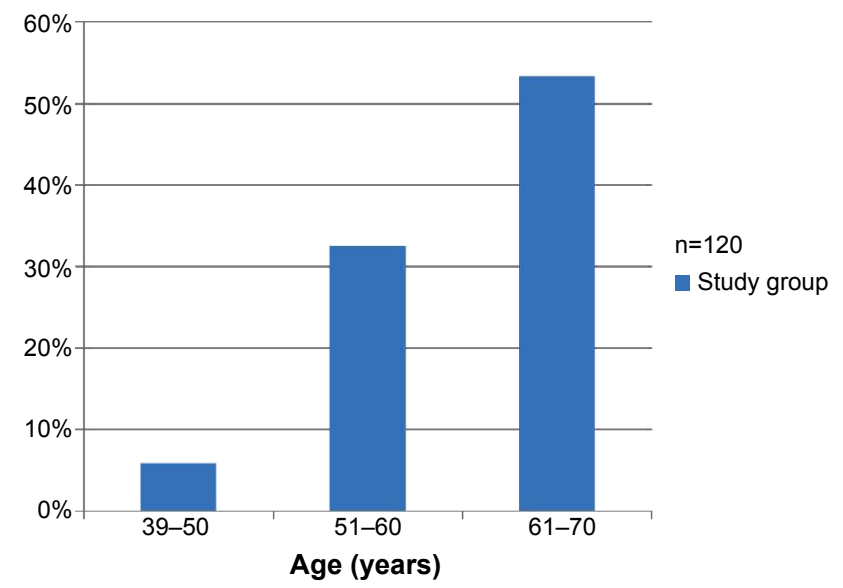

Figure 5 Multimorbidity by age groups in 1975.

area of ethnic and religious conflicts, where extermination methods are similar to those experienced by prisoners of concentration camps and are still practiced.

The study showed that the conditions at concentration camps had a negative impact on the health of former prisoners 5 and 30 years after leaving a camp. One of the consequences was premature aging as a result of multimorbidity, affecting almost all the body's organs and systems. The symptoms of premature aging manifested themselves mainly within 5 years of leaving a camp. Compared with the control group, the rate of urinary system dysfunctions was 15 times higher, the rate of psychological and skeletal dysfunctions was ten times higher, the rate of alimentary dysfunctions was eight times higher, and the rate of cardiovascular diseases was four times higher in the study group. The follow-up data gathered 30 years after leaving a camp show that, in both former prisoners and the population who had never been incarcerated, the differences between the control and the study group became less evident but remained statistically significant.

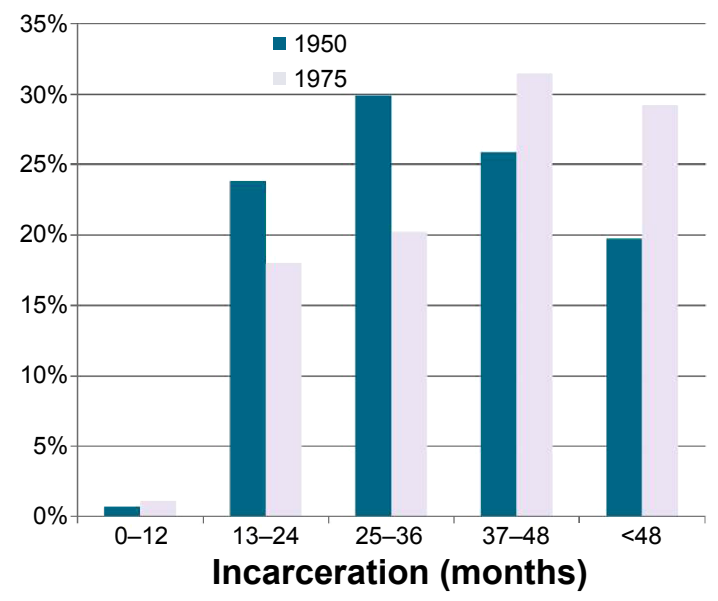

Figure 6 Effect of the duration of incarceration on multimorbidity. 
The rate of CNS diseases was four times higher in the study group than in the control group 30 years after leaving a camp, and the rate of cardiovascular diseases or skeletal system dysfunctions in this group was double that of the control group. These results correlate with the findings of other authors. For instance, according to Panasewicz, 1 year of incarceration corresponds to 4 years of normal life, ie, imprisonment speeds up the process of aging by 3 years on average. ${ }^{5}$ This is how Panasewicz simply explains the process of premature aging: excessive emotional stress leads to depression and sleep dysfunction, causing psychophysical disability and growing fatigue, which leads to chronically progressing asthenia and premature aging. The scientific research on multimorbidity mainly focuses on three systems: the CNS, cardiovascular system, and skeletal system, as was shown in Polish publications by Szwarc ${ }^{6}$ and Witusik, ${ }^{7}$ and foreign ones by Hermann and Thygesen ${ }^{8}$ or Eitinger and Strøm, ${ }^{9}$ who also mention alimentary system dysfunctions being statistically significant. The follow-up data collected 5 and 30 years after leaving a camp suggest that the rate of dysfunctions within the CNS was the highest and was rising with time. Other authors, eg, Zielina ${ }^{10}$ and Szymusik, ${ }^{11}$ also placed the CNS dysfunctions at the top of their list of dysfunctions after 20 and 30 years of leaving a camp, while Szwarc ${ }^{6}$ ranks them as second highest, and Witusik ${ }^{7}$ as the third highest. Szymusik ${ }^{12}$ also found that the rate of psychological diseases increased with time and affected almost all former prisoners of concentration camps, a finding that was supported by Gątarski et al..$^{13}$

The follow-up data collected from former prisoners indicate that multimorbidity is usually characterized by the coexistence of multiple somatic diseases that can frequently be linked with psychological dysfunctions. It was not uncommon for a survivor of a concentration camp to visit a doctor because of one somatic or psychological condition and to be diagnosed with several coexisting ones after a thorough interview, medical examination, and additional testing. This is one of the characteristics of multimorbidity that begins to manifest usually a few years after leaving, as indicated by the follow-up data gathered from former prisoners 5 years after leaving. The rate of multiple organ lesions was ten times higher in the study group than in the control group 5 years after leaving a camp, and two times higher 30 years after leaving a camp. The coexistence of several serious diseases in one survivor can be explained by the fact that one chronic disease had a negative impact on the whole body and caused multiorgan lesions. This hypothesis is supported by a study by Kłodziński, who noticed that multiorgan diseases were more frequent among former prisoners than in the general population. ${ }^{14}$

\section{Significant outcomes}

In summary, the significant outcomes of this study are as follows:

- Multimorbidity, premature aging, and increased mortality represent the principal consequences of incarceration in concentration camps.

- Multimorbidity affects mostly the CNS of former prisoners.

- Older age and longer duration of a camp stay are the main determinants of multimorbidity.

\section{Limitations}

The limitations of this study are the retrospective character of the analysis and recall bias.

\section{Conclusion}

The consequences of incarceration in concentration camps presenting as multimorbidity affect the majority of survivors. The coexistence of several chronic diseases is manifested mainly in older prisoners, who stayed at a camp longer. Their condition is most often characterized by premature aging with systemic inflammation and degenerative diseases, causing a dramatic increase in the mortality rate among that population. Low-grade systemic inflammation characteristic for cachexia could be the common determinant. Present times abound with areas of ethnic and religious conflict, where extermination methods are similar to those experienced by prisoners of concentration camps and are still practiced.

\section{Disclosure}

The authors report no conflicts of interest in this work.

\section{References}

1. Rogowski O, Shapira I, Bassat OK, et al. Waist circumference as the predominant contributor to the micro-inflammatory response in the metabolic syndrome: a cross sectional study. J Inflamm (Lond). 2010;7:35.

2. Fierla D. The Boer War 1899-1902. Warszawa: Bellona; 2002.

3. Gann L, Duignan P. Colonialism in Africa 1870-1970. Cambridge: Cambridge University Press; 1982.

4. Posner G, Ware J. Mengele: The Complete Story. New York: McGrawHill; 1986.

5. Panasewicz J. [Some timely pathologic problems of wartime]. Przeglad Lekarski Oświęcim. 1969;1:13-18. Polish.

6. Szwarc H. [Morbidity of former prisoners of nazi prisons and concentration camps]. Przegląd Lekarski Oświęcim. 1965;1:38-40. Polish.

7. Witusik WR. [Pathologic traces of imprisonment in concentration camp prisoners in the Oświęcim County]. Przegląd Lekarski Oświęcim. 1968;1:56-64. Polish.

8. Hermann K, Thygesen P. [The KZ syndrome; sequels of starvation eight years later]. Ugeskr Laeger. 1954;116(22):825-836. Danish.

9. Eitinger L, Strøm A. Mortality and Morbidity after Excessive Stress. Oslo: Universitetsforlaget; New York: Humanities Press; 1973. 
10. Zielina J. [Results of medical examinations of former inmates of Nazi prisons and concentration camps]. Przegl Lek. 1966;22(1):49-52. Polish.

11. Szymusik A. [Progressive asthenia in former prisoners of the Auschwitz concentration camp]. Przegląd Lekarski Oświęcim. 1964;1:23-29. Polish.

12. Szymusik A. [War invalidism among former prisoners of concentration camps]. Przegląd Lekarski Oświęcim. 1974;1:110-112. Polish.
13. Gątarski J, Orwid M, Dominik M. [The results of psychiatric and electroencephalographic examinations of 130 former prisoners of Auschwitz-Birkenau]. Przegląd Lekarski Oświęcim. 1969;1:25-27. Polish.

14. Kłodziński S. [A specific clinical state after imprisonment in the nazi camps]. Przegląd Lekarski Oświęcim. 1972;1:15-21. Polish.

\section{Publish your work in this journal}

Neuropsychiatric Disease and Treatment is an international, peerreviewed journal of clinical therapeutics and pharmacology focusing on concise rapid reporting of clinical or pre-clinical studies on a range of neuropsychiatric and neurological disorders. This journal is indexed on PubMed Central, the 'PsycINFO' database and CAS, and is the official journal of The International Neuropsychiatric Association (INA). The manuscript management system is completely online and includes a very quick and fair peer-review system, which is all easy to use. Visit http://www.dovepress.com/testimonials.php to read real quotes from published authors.

Submit your manuscript here: http://www.dovepress.com/neuropsychiatric-disease-and-treatment-journal 